\title{
How to beautify your old hospital
}

\author{
J H BARON
}

Sir Henry Wotton is usually remembered for defining an ambassador as "an honest man sent to lie abroad for the good of his country," but he equally pithily paraphrased Vitruvius's qualities of a building (strength, utility, and beauty): "Well building hath three conditions, commoditie, firmenes and delight." Hospitals are designed to produce health care and do so more or less effectively; not all contemporary hospitals fall down soon after they are completed, from lapses in design and execution; but few people expect hospitals to be designed and built to delight. Curiously, people who like their homes to be elegant, who museum-crawl and sight-see on holiday at home and abroad, are amazed when I suggest that a hospital should be beautiful.

Only during the last half of this century have ambitions like mine been considered to be eccentric. No one thought it odd that Hogarth painted a staircase well at St Bartholomew's Hospital, painted a portrait of the founder of the Thomas Coram Foundation for Children (the Foundling Hospital), or persuaded his artist friends to give their works to the Foundling Hospital, thus beautifying it and publicising the achievements of British artists. The Victorians expected their town halls and railway stations to be objects of wonder and beauty; the walls of some of their children's wards were covered with fairy tales and nursery rhymes in Doulton tiles; even workhouses sometimes had pictures on the walls (fig 1). Those who trained at Middlesex Hospital will remember its elegant panelled front hall with Cayley Robinson's "Acts of mercy" murals, the central circular table with the daily change of flowers, the brassbuttoned frock-coated uniformed porters, and the singular lettering of the ward names on the direction boards. Compare this with most hospital entrances today.

J H BARON, DM, FRCP, consultant physician

Correspondence to: 36 Abbey Gardens, London NW8 9AT.
If you think it worth while to beautify your old hospital the following article may help you to do so. A separate article gives ideas on obtaining works of art for new hospitals. ${ }^{3}$

\section{Apathy and antipathy}

In trying to beautify your hospital do not be put off by lack of interest from other people. Achievement is still possible in the face of amused tolerance so long as you press on regardless. Actual antagonism will, however, stop you. You will fail if you meet explicit opposition from any person in power. I made hints at two hospitals world famous for their clinical science. In one "the sad [fact is], even in periods of financial boom, no one [will] consider art as a necessary portion of hospital expenditure." In the other the dean did consult his advisory committee and heads of department: "there wasn't a very enthusiastic response. Perhaps we are all a bit overwhelmed with the general gloom, particularly on the NHS side. ..." If you are faced with such reactions, give up and wait for a new dean who is "interested in changing what is unquestionably one of the most squalid hospitals in all Britain."

THE COMMITTEE

In any part of British public life, and especially in a hospital within a bureaucratic health service, a committee is necessary for any new venture to succeed. Some hospitals give these committees conventional names: an art or arts committee, a fine arts board, a history and works of art committee; I called ours the beautification committee. You will need terms of reference, which should be as wide as your interests. Also, you must report to someone, such as the unit management team of a hospital, or the special trustees if they are the prime paymaster.

A committee will also serve to spread the aesthetic responsibility. The directors of the National and Tate Galleries cannot buy anything on their own decisions: the trustees have to approve every purchase so that the responsibility for spending public money can be spread among, and any obloquy borne by, many broad shoulders. Similarly, in a hospital anything you do will receive strong criticism, so let it be clear that decisions have been shared, and conclusions reached, by thoughtful people.

The committee must be small and meet regularly on a specific day at a specific time. If you are the chairman you will need an interested administrator, an interested nursing officer, and (the key figure) a committee 


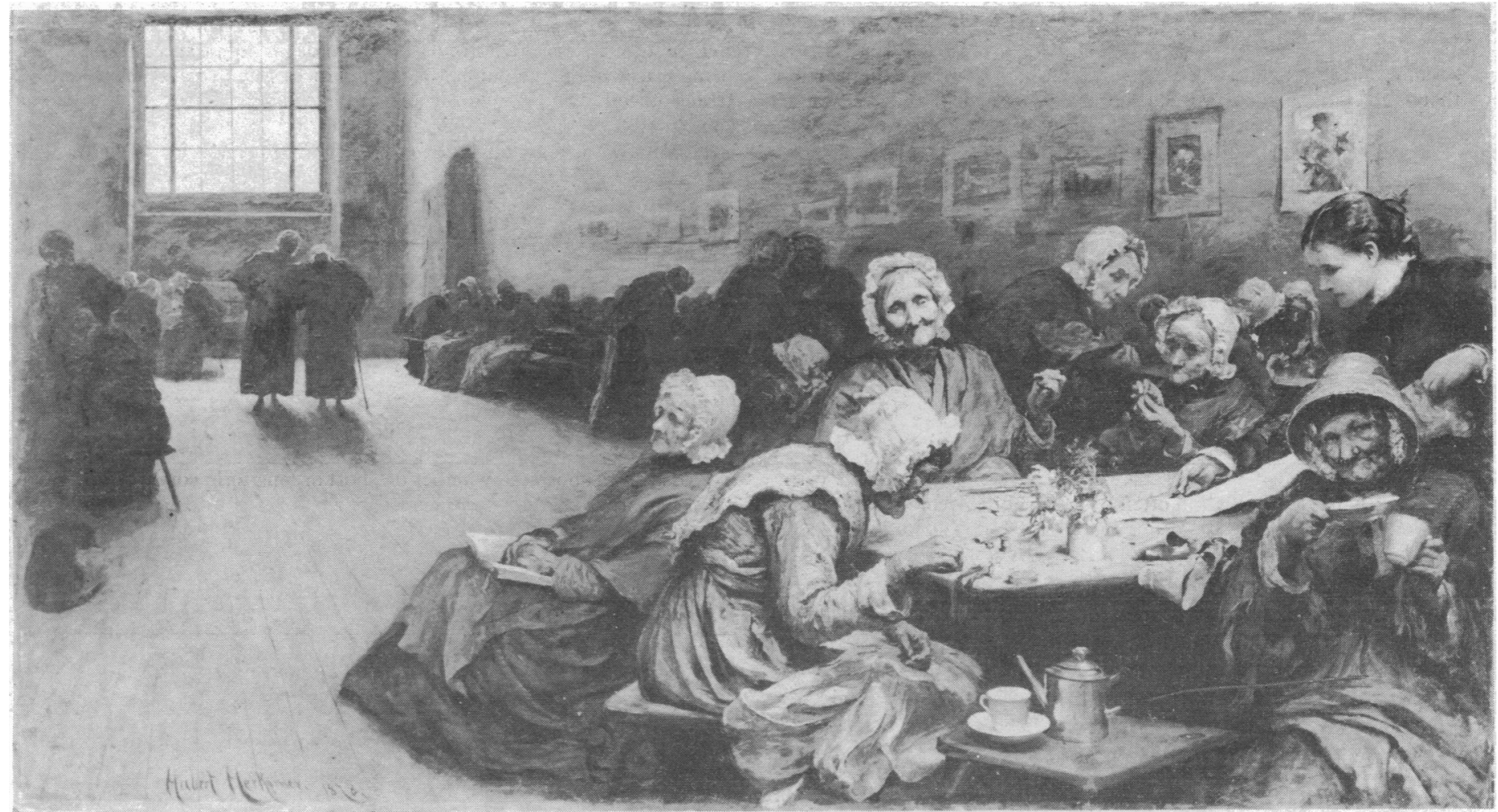

FIG 1-Sir H Van Herkomer (1849-1914). Eventide-a scene in the Westminster Union, 1878. Walker Art Gallery, Liverpool.

secretary who is devoted to the topic. The committee secretary can come from any discipline and may, for example, be the voluntary services organiser if you have one or an outside art lover in an honorary capacity.

\section{What to beautify}

BUILDINGS

Every hospital has been designed by an architect with skill, devotion, and artistry. Often the original drawings or engravings survive or can be found in illustrations in old books, local newspapers, the topography collection of your library, architectural journals, or national periodicals such as the Illustrated London News. These designs will grace an entrance hall or corridor, framed as pictures or as black and white photographic enlargements blown up to the size of the whole wall.

All too many British hospitals were built a century ago as Victorian workhouse infirmaries for the sick poor. The 19th century buildings have usually been altered or extensions of every style added, leaving an architectural mish mash. But sometimes the original buildings have not been so disturbed. If you can persuade the works department to remove decades of grime you may be pleasantly surprised at the splendours of Victorian brickwork, detailings, and architecture. You may find your principal work of art is your own building. If so, cherish it. See that there is an overall colour scheme for the exterior woodwork and drainpipes, that the roofing is repaired in colour and texture similar to the original. (If you cannot afford new real slates at least have simulated ones.) If there are original iron railings, fences, balconies, or walkways try to keep them and prevent their replacement by barbed wire or chicken fencing. Similarly, the original lamps may have been gas lit; they should be adapted to electricity rather than replaced by concrete posts.

Instead of a brand new hospital you will probably be given new additions for outpatients or radiography; if you are not careful some prefabricated concrete box will rise up and mar the old ensemble. Try to persuade your district to set up a design panel that must see and approve aesthetically as well as functionally all new additions to any hospital in the district so that representations can be made before it is too late and the juggernaut of the National Health Service planning process rolls over you.

\section{GARDENS}

These are best left to experts, one or two of whom are likely to be found on your committee or can be coopted. Your garden subgroup should take a total look at the hospital campus and make recommendations through your committee to the unit management team about the lawns, trees, paved areas, benches, tubs, climbers, plants, ponds, and fountains, not to forget the litter bins. There may be scope for some schemes with indoor plants, but every scheme must be manageable either by named and interested volunteers from staff or friends or by contract with a garden firm.

\section{HOSPITAL ENTRANCES}

These come in all sizes and shapes but are rarely welcoming. The casualty department is often approached through a tiled tunnel or corridor lined with wheelchairs. The outpatient department may be hidden down a side street and the waiting hall filled with broken chairs, tattered magazines, or blaring television, ash trays, and countless notices, hortatory or admonitory, ranging from injunctions to tell the desk if you have changed your name or your family doctor to warnings about smoking, drinking, and the problems and consequences of life after sex.

Most visitors come into a main courtyard and are immediately made to feel unwelcome by a kaleidoscope of notices forbidding them to park (reserved for consultants), warning them that they park at their own risk, or telling them how to get to the special clinic or the mortuary. Inside, the main hall will be cluttered with more notices, telephone booths, fire extinguishers, post boxes, flower stalls, newspaper kiosks, and sometimes a reception desk with pigeon holes for letters, fuse boxes, and a. key board. A sympathetic architect should be commissioned to design a comprehensive plan for refurbishing, lighting, and decorating your front hall. He may be able to bring the porter's desk forward and flank it with a general shop and a flower stall with telephone alcoves at each end. The clutter of objects and notices can be removed and tied up visually. It is often helpful to lower the ceiling, install concealed lighting, and bank the direction signs into blocks of colours to complement the whole colour scheme.

\section{NOTICES}

Notices spring up everywhere and can mostly be removed. A map is ideal with a plan of the hospital or even a model. Obviously, directions are needed to the different wards and departments. Most hospitals have been persuaded by the Department of Health and Social Security to use their standardised lower case sanserif type face for every sign. Some people like it. It is a matter of taste. Such lettering is ideal for motorway signs to be read clearly and easily as you rush past in your car. I am depressed by seeing the same institutional lettering in every hospital. It may suit hospitals that look like 
motorways. For your hospital look at other type faces in the catalogues of notice makers: Times New Roman may suit your own buildings best. Ideally your hospital, and indeed your district, should have a corporate image, with a logo and an elegant type face for everything it presents to the public, whether on the flags flying overhead, the vans going through the streets, the signs over the entrance, the writing paper, or the mail franking.

\section{CORRIDORS}

Until recently most district and many university hospitals were designed on the Nightingale pattern-several ward blocks of two or three storeys branching off a long corridor. This design allows natural light and ventilation to enter the wards from two sides and separates each ward from another by a distance sufficient to lessen cross infection and noise. Another happy consequence of the design is that staff meet each other walking up and down the corridors and do not spend their time in isolation waiting for, or crowded into, the lifts of the vertically designed hospitals of today. Long main corridors are often, however, the most aesthetically depressing part of a British hospital. The visitor's heart sinks as he sees a gloomy prospect with the end scarcely in view. This will often be in a grubby decorative state but will still be gloomy when freshly painted in a single drab colour. ${ }^{3}$ Ask your architect to consider breaking the corridor into different coloured areas. He may want to coordinate and classify his colour on the lines of a scheme such as the Munsell system and then give you a linking line of colour with a sequence of hues to each bay (fig 2).

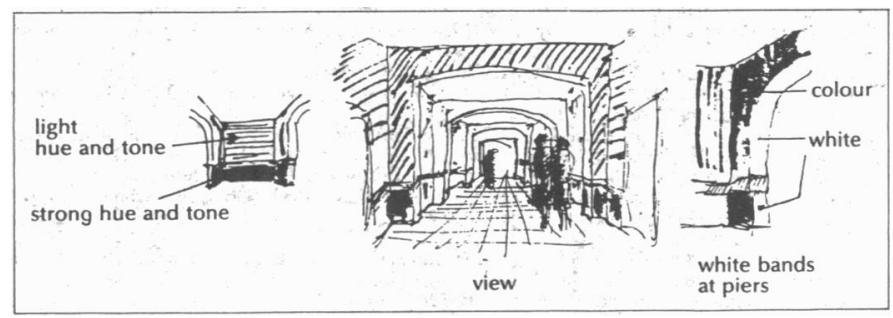

FIG 2-Corridor colour scheme designed by Robert Radford, 1984. "The objective is to provide a linking line of colour to the chair rail and a sequence of hues to each bay emphasised by the strong hues below the chair rail, punctuated by white elements."

\section{MURALS}

You may have an entrance stairway or foyer or a busy corridor leading to outpatients. These can be key areas visually and cry out for murals. They are, however, places of continual movement in which it is perhaps undesirable for people to stop, stand, and scrutinise recognisable representational objects in a mural. An abstract pattern may work best. The mural must work as a simple immediate effect, unfolding as the visitor walks past and by its optimism relieving the tension of those who are worrying about themselves or others.

Abstract murals have other advantages. The men's day room of the Chronic Diseases Hospital on Welfare Island, New York, had had "a photomural of girls in bathing suits. The confined men, aroused by the sight of scantily clad females had defaced the photomural with pornographic grafitti." In 1940 Ilya Bolotowsky, while employed by the mural divison of the Federal Arts Project, was commissioned to paint instead a 50 foot long by seven foot high canvas. The curved wall was divided horizontally by a hand rail. Below was plain grey brown against which chairs could be placed. Above were blue, green, and white semiabstract areas that suggested tautly stretched sails, reflection of sails on water, or keel and rudder forms. Bolotowsky had found the room depressing and tried to evoke the outdoors and sports to create a pleasant optimistic environment. The doctors' committee was so pleased that the non-figurative substitute had "kept the patients quiet" that they commissioned another mural from Bolotowsky. ${ }^{4}$

In other departments such as visitors' waiting areas, or for those sitting in chairs or lying on stretchers (waiting to undergo radiotherapy, for example) pastoral scenes or flowers may be more restful. Day areas may be cheered by local topography, past or present. The needs of children's units are obvious.

\section{PICTURES}

These must be chosen for size and colour for a specific site. They are needed particularly in long corridors, waiting areas, day rooms, and foyers outside wards. Persuade your colleagues to donate, or at least pay for, framed photographs of the notable who gives his name to their wards-
Addison, Fleming, Churchill, for example. You may be asked for pictures for individual offices, in which case you should have an operational policy that pictures are provided from hospital funds for public spaces alone, these being places where the public walks and offices seen by patients or visitors. Other office holders should certainly be encouraged to have pictures, but these should be their own.

Hospital wards have surprisingly little space for pictures. Usually only a few walls are sufficiently bare for hanging because most walls in a ward are taken up with windows or cupboards or have wires trailing and tubes attached. Even in side wards you should be careful not to trap a patient face to face with an incompatible picture for days or weeks on end. Perhaps we should follow the example of some American hospitals where volunteers wheel round an "art cart" every couple of days so that patients can change the pictures on their walls just as they change the books from the hospital library.

\section{ARTISTS}

Artists in the hospital, whether on short or long term commissions, or as part of an artist-in-residence scheme, act as catalysts by their very presence; staff, patients, and visitors can see them working and can talk and listen to them. This should ensure a favourable climate of opinion for further beautification.

\section{Conservation}

Pictures cannot be left to look after themselves anymore than laws can be left to enforce themselves. A hospital should not buy, and certainly not borrow, works of art unless someone is prepared to catalogue, conserve, and generally keep an eye on them to prevent loss or damage. This task should be assigned to one interested and obsessional person, who could be an expert volunteer or someone from the administrative, nursing, or paramedical staff.

If you borrow from public bodies you will have to insure the work at their valuation; few hospitals have either the time or expertise to deal with such administrative problems. For example, in 1965 the Walker Art Gallery lent some pictures to the Liverpool Royal Infirmary, which were hung in the entrance hall; the security arrangements were later considered to be inadequate, and the gallery withdrew its pictures. ${ }^{5}$ Pictures continually disappear from hospitals. Theft is probably rare. More often the pictures are taken down and not properly stored when a ward or corridor is cleaned. When the decorations are completed the pictures are not rehung but are instead mislaid, discarded, or lost. The donor, who in 1912 gave tens of thousands of pounds to each of at least eight hospitals to bear the name of his widow Annie Zunz also gave a portrait of her to hang in one of these wards. Who can find Annie Zunz today? 6

Anything hanging on a hook can all too easily be carried off. The pictures must be fixed firmly to a wall by screws, with mirror plates for example. If the hospital engineers cannot spare appropriate staff for this task then professional picture hangers will be needed. The pictures must not be exposed to intense light, heat, wind, rain, or humidity.

All pictures need framing, and all water colours and engravings and some paintings need glazing too. Works on paper need mounting on acid free boards. Even a large occupational therapy department is unlikely to be able to cope with such requirements, and professional framers should be used who will give thoughtful and individual consideration to the type of mount and frame suitable for each work.

Pictures need labels to tell the viewer at least the title and the artist. Labels are best pinned to the lower horizontal of the frame, and the size, colour, and lettering should depend on the colour and texture of the picture mount and frame; again, these are usually best done professionally. Large works such as murals deserve a large label mounted on the wall and giving not only title, artist, and date but also the occasion of its commissioning and the names of donors. A few lines explaining the composition may also be helpful.

Quite apart from the simple labels, you should have a card index detailing for each work the artist with his date of birth (and, if appropriate, death), the date and title of the composition, the medium-for example, oil, water colour, engraving, etching - the material - for example, canvas, board, paper-the date of purchase, the cost and source of funds (or from whom borrowed, when, and for how long) and its location. Some of these data can be turned into a catalogue that can be duplicated or printed according to your resources.

\section{Finance}

The old board of governors voluntary hospitals all had endowment funds, which have been preserved in the care of special trustees. You may be able to 
persuade the trustees that they should spend some of their income, or even their capital, on works of art. Some have already allotted tens of thousands of pounds for initial purchases and have then provided up to $\$ 10000$ a year for staff, further purchases, and conservation. Others spend nothing on art.

If your special trustees refuse you money for works of art or if you are in an old municipal county council hospital without special trustees you may find your district has some free monies such as their share of the old area health authority's trust funds. Your unit too may have some unallocated money from donations or legacies from grateful patients and well wishers. Funds may be raised by friends or volunteers, especially for specific purposes like pictures for a refurbished day room.

Study some of the available booklets ${ }^{7-11}$ for ideas on funding and names and addresses. ${ }^{812}$ If you are in London discuss your requirements with the visual arts officer of the Greater London Arts Association. The Public Art Development Trust will tell you about the Greater London Arts Association and King's Fund Mural Scheme. Outside London you should see the visual arts officer of your regional arts association and the director of your local art gallery. Pictures can be borrowed from Paintings in Hospitals and prints from the British Red Cross Society. The insides of hospitals are not usually ideal for sculpture, and public funds may be available for large sculptures strategically cited outside a hospital. The Crafts Council may provide funds for craftwork such as wall hangings or ceramics. In addition, the Manpower Services Commission may help you with a project for training the unemployed as craftsmen in the arts, or you can approach local industry and national foundations.

You must be able to steel yourself against criticisms of your aesthetic judgment and taste in any beautification you promote. You will probably be wise to avoid, even if you are able to obtain, exchequer funds from the hospital budget. If a work of art is paid for with hospital money you may find that "the correspondence columns of the local newspaper immediately [fill] up with letters from $\mathrm{Mr}$ Disgusted Taxpayer (who else?) - a man who [doesn't] know anything about art, but [knows] what he dislikes. If this money had not been wasted on so-called modern art my grannie could have had her teeth taken out and a new gas stove put in."13

\section{The visit}

The NHS, like all great institutions, has an inertia of its own that can stop all your initiatives from starting and prevent the completion of any begun.
You may speed up your project by the usual wheedling and negotiations, but faced with an impasse play your ace, the visit. Arrange for some dignitary (be it royalty, the regional chairman, or the mayor) to come on a specific date to open one of your schemes and unveil an appropriately worded plaque in the presence of an invited audience. You will be pleasantly surprised how the impossible begins to happen at once, that timetables of work are kept, and that the hospital, or at least the professional route of the tour by the dignitary, is cleaned.

\section{Conclusion}

Having read this article you may want to beautify your hospital and you will have learnt that you can do so just as you can achieve anything else in the health service given vision, energy, time, patience, a lack of enemies, a working committee, and sufficient guile to know both the regulations that run the NHS and the way to outwit them.

Many have helped and are thanked elsewhere. ${ }^{7}$ In this endeavour, as in so much else, I was inspired by Wendy Baron.

\section{References}

1 Wotton H. Elements of architecture. London: John Bill, 1624:1.

2 Baron JH, Greene L. Funding works of art in new hospitals. Br Med $\mathcal{J}$ (in press).

Agate J. Colour in hospitals. World Medicine 1969;20 May:13-7.

Herbert RL, Apter SL, Kenney EK, eds. The Société Anonvme and the Dreier Bequest at Yale University: a catalogue raisoné. New Haven: Yale University Press, 1984: 75-80

Brewer C. Liverpool Royal Infirmary, 1887-1978. Liverpool: Area Health Authority (Teaching), 1980:131.

6 Rosse EM. The lady missing from St Mary's. Nor West 1984;2:2

Baron JH, Hadden M. St Charles Hospital works of art. London, 1984. (Obtainable from St Charles's Hospital, London W10.) 8 Coles P. The Manchester Hospital Arts Project. London: Calouste Gulbenkian Foundation, 1981.

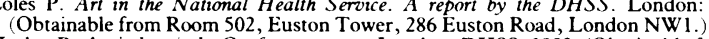

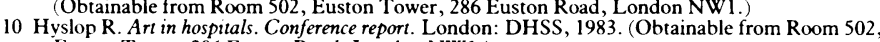
Euston Tower, 286 Euston Road, London NW1.

11 Reed E. Art in hospitals. Arts Review 1983;13 May:259.

12 Townsend P, ed. Art within reach: artists and craftworkers, architects and patrons in the making of

public art. London: Art Monthly/Thames and Hudson, 1984.
13 Keep P. Having an art attack. World Medicine $1983 ; 25$ June:22.

(Accepted 11 fuly 1984)
Does endoscopy affect the concentrations of gastrointestinal hormones if these are measured within three hours of the procedure?

The brief answer to this is not appreciably. By far the biggest influence on the gastrointestinal hormone concentrations is food and provided that the patient does not eat after the procedure, hormone levels should remain within the normal fasting range. Acutely, motilin release is affected by bowel distension-for example, with air inflation of the small intestine-as is gastrin with inflation of the stomach. Such influences, however, should have completely disappeared three hours later. While endoscopy itself does not produce sustained changes in gut hormone release, accompanying medication may do so. Thus if for any reason an anticholinergic drug has been administered, some rise in gastrin may be expected due to the inhibition of gastric acid secretion-S R BLOOM, professor of endocrinology, London.

Despite increasing complexity in the manufacture of wrist watches, anecdotal accounts that certain people in illness, and sometimes in health, cannot wear a watch without affecting the function of that watch still occur. Is there any scientific basis for this phenomenon?

Experts accept that the phenomenon exists and that even quartz and pulsar watches are not entirely exempt. Spring watches may be affected by changes in magnetic fields, temperature, atmospheric pressure, alterations in position, lubrication, and wear on moving parts. Faults may occur from irregular winding: if wound regularly to $1 \frac{3}{4}$ turns the balance is less likely to be influenced by the movements of the wearer. Dust or loss of lubrication will affect pivot friction, introducing gravity effects: the watch will go slower when hanging or on edge than when worn dial upwards. Vibration effects, as with thyrotoxicosis, may cause inaccurate escapement. Rises in temperature are more likely to cause slowing due to expansion of the hairspring and watches commonly go slightly faster in winter than in summer. Quartz watches with no moving parts may be influenced by aging of the crystal, thermal drift, and cleanliness.

These recognisable causes do not explain each individual circumstance; anecdotal accounts of altered behaviour of watches in pathological circumstances (during periods of sleep deprivation, hypokinesia, fatigue after arduous exertion, or prolonged emotional stress), temporary changes in the geophysical environment-solar activity, magnetic fields-or even with unusual work/rest programmes appear to share a common factor in alterations in the person's geomagnetic field. Changes may be measured by SQUID (a superconductivity quantum interference device) showing: (a) increased heterogeneity of skin potentials, with areas of high electrical conductivity, $(b)$ desynchronised or weakened amplitude of circadian fluctuations, and (c) short period oscillations in sympathetic/parasympathetic tone. The interaction of changes in personal geomagnetic fields and mechanical devices (watches, pacemakers) is poorly understood, with very little hard data available. (I would be happy to receive personal accounts of particular experiences with the wearing of watches in order to facilitate a more scientific inquiry at a later date.) - E M R CRITCHLEY, consultant neurologist, Preston. De Carle D. Complicated watches and their repair. London: Northwood Publ, 1956.
Good R (ed). Britten's watch and clockmakers handbook. 16th ed. London: Eyre Matheson, 1978

Plonsey R. The nature of sources of bioelectric and biomagnetic fields. Biophys $\mathcal{f}$

1982;39:309-12.
Rawlings AL. The science of clocks and watches. Trowbridge and Esher: Redwood Burn, 1974.

Ryzhikov GV, Kuz'menko VA, Buluev AB. Effect of disturbances of the geomagnetic field on the circadian rhythm of physiological functions. Human Physiology $1982 ; 8: 87-93$.

yzhikov GV, Raevskaya OS, Gumenyuk VA, Kaptsov AN. Effect of the geomagnetic field and nervous and mental strain on electric resistance in biologically 